University of Louisville ThinkIR: The University of Louisville's Institutional Repository

Electronic Theses and Dissertations

5-2019

\title{
Inspiratory muscle recruitment during swallow and a comparison across airway behaviors.
}

Allison V. English
University of Louisville

Follow this and additional works at: https://ir.library.louisville.edu/etd

Part of the Speech Pathology and Audiology Commons

\section{Recommended Citation}

English, Allison V., "Inspiratory muscle recruitment during swallow and a comparison across airway behaviors." (2019). Electronic Theses and Dissertations. Paper 3204.

https://doi.org/10.18297/etd/3204

This Master's Thesis is brought to you for free and open access by ThinkIR: The University of Louisville's Institutional Repository. It has been accepted for inclusion in Electronic Theses and Dissertations by an authorized administrator of ThinkIR: The University of Louisville's Institutional Repository. This title appears here courtesy of the author, who has retained all other copyrights. For more information, please contact thinkir@louisville.edu. 


\title{
INSPIRATORY MUSCLE RECRUITMENT DURING SWALLOW AND A COMPARISON WITH OTHER AIRWAY BEHAVIORS
}

\author{
By
}

\author{
Allison V. English \\ B.H.S.- University of Kentucky, 2017

\begin{abstract}
A Thesis
Submitted to the Faculty of the School of Medicine of the University of Louisville in Partial Fulfillment of the Requirements for the Degree of
\end{abstract}

Master of Science

in Communicative Disorders

Department of Otolaryngology - Head/Neck Surgery and Communicative Disorders University of Louisville

Louisville, Kentucky

May 2019 
(C) 2019

Allison V. English

All rights reserved 



\title{
INSPIRATORY MUSCLE RECRUITMENT DURING SWALLOW AND A COMPARISON WITH OTHER AIRWAY BEHAVIORS
}

\author{
By \\ Allison V. English \\ B.H.S.- University of Kentucky, 2017 \\ A Thesis Approved on
}

April 22, 2019

by the following Thesis Committee:

Teresa Pitts, Ph.D., Thesis Advisor

Rhonda Mattingly, Ed.D.

Alan Smith, Ed.D. 


\section{DEDICATION}

To all of the strong women in my life, thank you for inspiring, supporting, and empowering me. 


\section{ACKNOWLEDGMENTS}

First and foremost, I thank those directly involved in this research process. I thank Dr. Pitts for her mentorship and support over the past two years; Dr. Smith and Dr. Mattingly for their guidance and encouragement as members of my thesis committee; and Mitch and Alyssa for their help and friendship along the way.

Additionally, I thank my husband, Connor, for his constant support and willingness to answer all of my statistics questions. And I cannot go without thanking all of my sweet friends in the program, especially Emily, for the countless laughs and cups of coffee we have shared throughout our time at the University of Louisville. 


\begin{abstract}
INSPIRATORY MUSCLE RECRUITMENT DURING SWALLOW AND A COMPARISON WITH OTHER AIRWAY BEHAVIORS
\end{abstract}

\author{
Allison V. English
}

April 22, 2019

During swallow, a negative esophageal pressure is present that, along positive pressure from the tongue, which works to move the bolus through the pharynx into the esophagus. This negative esophageal pressure is thought to be produced via recruitment of chest wall inspiratory muscles (diaphragm and parasternal). This current study aimed to examine respiratory muscle recruitment across behaviors which have known inspiratory muscle activity (eupnea, augmented breath and cough) and compare to swallow. It was hypothesized that there would be no significant difference in amplitude and muscle recruitment over $75 \mathrm{~ms}$ between swallow and eupnea, but cough and augmented breath would be significantly larger. Electromyograms (EMG) from the costal diaphragm and parasternal muscles were recorded and analyzed in five freely breathing anesthetized cats. Muscle recruitment was examined by taking both the root 
mean square over the initial $75 \mathrm{~ms}\left(\mathrm{RMS}_{75}\right)$ of each behavior and the maximum amplitude of muscle activity for the total duration of the behavior. Results found that there was a significant difference for maximum amplitude of muscle activation across all behaviors for the parasternal and for augmented breath and cough for the diaphragm. Muscle recruitment of parasternal was significantly different from swallow for the behavior of eupnea. These results, along with a growing body of evidence, provide credence to the theory that inspiratory muscle activity is part of the swallow central pattern generator. This work could provide needed clinical information for the evaluation of dysphagia in at-risk patients. 
TABLE OF CONTENTS

PAGE

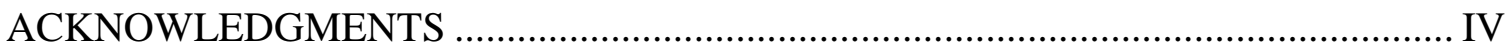

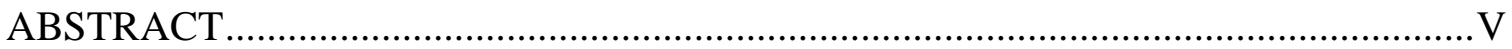

LIST OF FIGURES ……………………………………………………….....

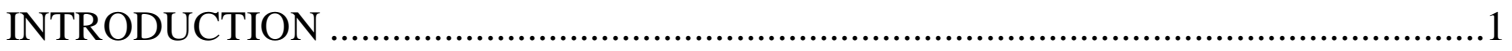

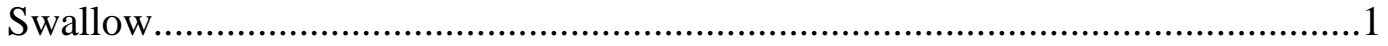

Dysphagia in the spinal cord injury population ....................................................

Inspiratory activity during swallow ............................................................

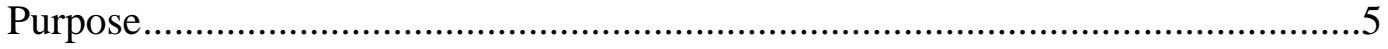

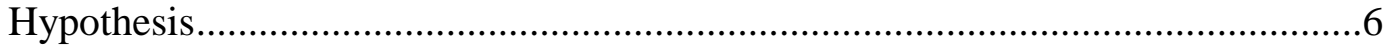

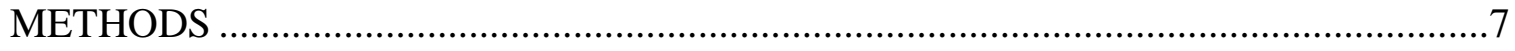

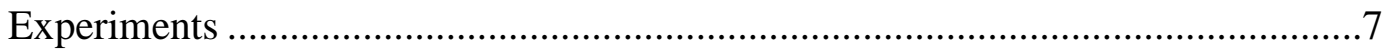

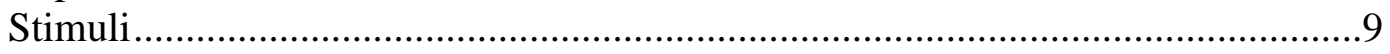

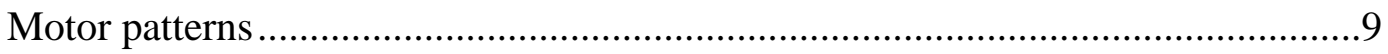

Data processing and statistical analysis .............................................................10

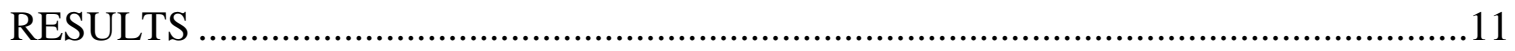

Inspiratory muscle activation across behaviors ....................................................11

Correlation between diaphragm and parasternal activation...................................11

Correlation between esophageal pressure and muscle activation ..........................11

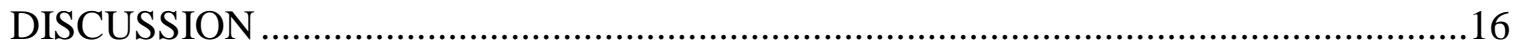

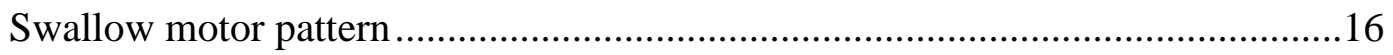

Recruitment of inspiratory muscles across airway behaviors ................................17

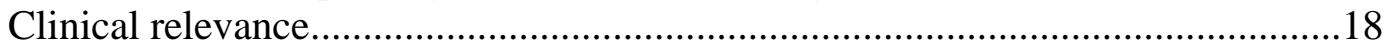

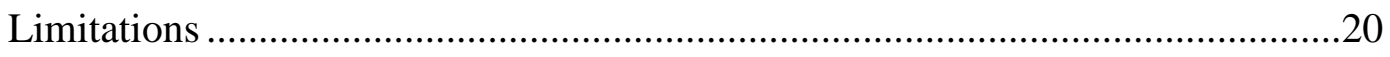

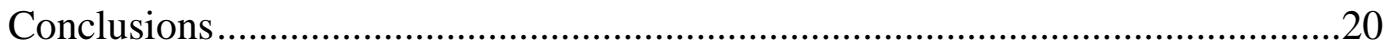

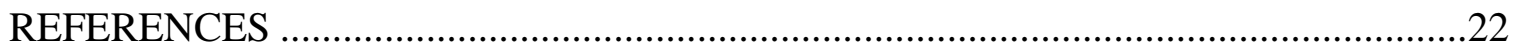

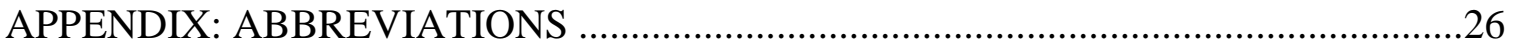

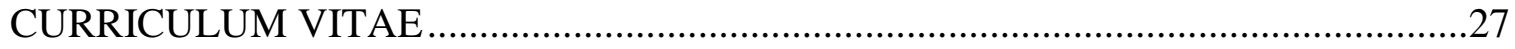

vii 


\section{LIST OF FIGURES}

FIGURE

PAGE

1. Motor patterns utilized to identify swallow..................................................... 13

2. Motor patterns utilized to identify cough............................................................... 13

3. Motor patterns utilized to identify augmented breath (sigh). ................................ 14

4. Overlapping maximum amplitudes of the diaphragm during different behaviors:

Eupnea (blue), sigh (orange), swallow (red), and cough (purple)................................ 14

5. Overlapping maximum amplitudes of the parasternal during different behaviors:

Eupnea (blue), sigh (orange), swallow (red), and cough (purple)................................ 15 


\section{CHAPTER 1}

\section{INTRODUCTION}

\section{Swallow}

Swallow is a vitally important airway protective behavior that moves food/liquid from the mouth to the stomach (Matsuo, 2008). Swallow is comprised of three phases (oral, pharyngeal and esophageal) and four stages (the oral phase is comprised of bolus preparation and transport) (Lang, 2009). During the pharyngeal phase of swallow several steps, such as epiglottic retroflexion and hyolaryngeal elevation, work to ensure protection of the airway by transporting the bolus away from the larynx and towards the esophagus (Matsuo, 2008). However, when the act is not performed properly food/liquid can enter the larynx (i.e penetration) and/or the trachea (i.e aspiration) (Robbins, Coyle, Rosenbek, Roecker, \& Wood, 1999). Certain populations are at a higher risk of dysphagia and aspiration, such as stroke victims, those with neurological disorders, and individuals suffering from traumatic brain injury and/or spinal cord injury (Dray, Hillel, \& Miller, 1998; Mandaville, Ray, Robertson, Foster, \& Jesser, 2014; Martino, Foley, Bhogal, Diamant, Speechley, \& Teasell, 2005; Wolf \& Meiners, 2003)

\section{Dysphagia in the spinal cord injury population}

According to Chaw, Shem, Castillo, Wong, and Chang (2012), although it can cause serious medical complications, dysphagia is an often under-recognized difficulty in individuals following a cervical spinal cord injury (cSCI). Dysphagia can lead to serious pulmonary and nutritional complications as well as a decrease in quality of life in 
affected individuals (Chaw, Shem, Castillo, Wong, \& Chang, 2012; Eslick \& Talley, 2008). In their prospective study, Shem, Castillo, and Chang (2011) found that incidence of dysphagia in individuals with tetraplegia is approximately $40 \%$. It was also found that there are certain factors that can increase patient's risk for dysphagia following a cSCI, including age and presence of nasogastric and/or tracheostomy tubes. Other studies by Kirshblum, Burns, Biering-Sorensen, Donovan, Graves, Jha, Johansen, Jones, Krassioukov, Mulcahey, Schmidt-Read, and Waring (2011) and Wolf and Meiners (2003) reveal that a significant percentage of patients will present with dysphagia following cervical spinal cord injuries. Additionally, Shem, Castillo, and Chang. (2011) conclude that because individuals with dysphagia are at a higher risk for pneumonia, early diagnosis of dysphagia can lead to prevention of aspiration pneumonia and its accompanying complications.

Pneumonia is a serious respiratory complication that greatly impacts individuals with spinal cord injuries (Jackson \& Groomes, 1994). According to the National Spinal Cord Injury Statistical Center (2019), it is one of the causes "of death that has the greatest impact on reduced life expectancy" (p. 2) in this population. Jackson and Groomes (1994) found in their study that $67 \%$ of patients with spinal cord injuries experienced respiratory complications, of which $31 \%$ were pneumonia. In the group of individuals with injuries at cervical level one to four, pneumonia was the most commonly occurring respiratory issue at 63\% (Jackson \& Groomes, 1994). Pneumonia occurred in 28\% of the patients with an injury at cervical level five to eight (Jackson \& Groomes, 1994).

An additional clinical complication is that when an aspiration event occurs it is often silent (i.e no cough, throat clear, or outward sign/symptoms) (Smithard, 2015). In a 
retrospective study by Garon, Sierzant, and Ormiston (2009), 2000 patients were evaluated using videofluoroscopy to determine the presence of aspiration. Of these patients, 1,012 individuals experienced aspiration and silent aspiration was observed in 550 of those patients. Other retrospective studies have shown rates of $25-30 \%$ of individuals with dysphagia experiencing silent aspiration in the inpatient setting (Ramsey, Smithard, \& Kalra, 2005). Because silent aspiration can go undetected for extended periods of time, it places individuals at an even higher risk for developing pulmonary complications due to the lengthened period of ingestion of food or liquid into the lungs (Garon, Sierzant, \& Ormiston, 2009). Kirshblum, Johnston, Brown, O'Connor, and Jarosz (1999) found in their study that the presence of a tracheostomy or ventilator and an anterior approach of cervical surgery are two medical interventions that are significantly related to presence of dysphagia in the cSCI population. As these interventions place the $\mathrm{cSCI}$ population at greater risk for aspiration and silent aspiration, heightened focus should be placed on identification and treatment of dysphagia to decrease the chance of morbidity associated with aspiration.

\section{Inspiratory activity during swallow}

In his writings, Marckwald describes his investigations of diaphragm activity during swallow in the rabbit. He discusses the phenomenon referred to by himself and other researchers as "the respiration of swallowing" (Marckwald, 1888). This respiration of swallowing is also referred to as the "schluckatmung" in German or "swallow breath". Through his research, Marckwald made several observations and conclusions regarding the activation of the diaphragm during swallow and its importance, which helped to inform and inspire research within this lab. He sums up his results in two conclusions. 
One, that the center for swallowing, the glossopharyngeal nucleus, and the center for respiration work in very close connection but that swallowing occurs in a way completely different from respiration (Marckwald, 1888). Two, the center of swallow acts differently from the center for respiration in that rather than being automatically, constantly active, it is only stimulated by the act of swallowing (Marckwald, 1888). Finally, he states that "therefore, the so-called "respiration of swallowing" has not the importance of a respiratory movement, but it represents a very important occurrence in the action of deglutition, namely, the inhibition of respiration.” (Marckwald, 1888, p. 136)

Historically, inspiratory musculature activation has been considered irrelevant to the function of the swallow behavior. However, consistent observations of activation of the diaphragm during the swallow indicate that muscles of inspiration may play a role on swallow (Marckwald, 1888; Pitts, Poliacek, Rose, Reed, Condrey, Tsai, Zhou, Davenport, \& Bolser, 2018). There have been observations of diaphragm activation during swallow in both human and animal models (Ertekin, 2014; Hardemark Cedborg, Sundman, Boden, Hedstrom, Kuylenstierna, Ekberg, \& Eriksson, 2009; Pitts, Poliacek, Rose, Reed, Condrey, Tsai, Zhou, Davenport, \& Bolser, 2018). It has been questioned whether the activation of the diaphragm during swallow is creating a force that acts on the swallow or is simply acting as a brace for the thoracic cavity during the behavior. (Hardemark Cedborg, Sundman, Boden, Hedstrom, Kuylenstierna, Ekberg, \& Eriksson, 2009). This study operates under the belief that the former is true. Furthermore, incidence rates of dysphagia in cervical spinal cord injury patients, in which the innervation of the diaphragm and parasternal muscles are compromised, indicates a potential relationship 
between these muscles and the swallow. Continued research must occur to further our understanding of the role of inspiratory musculature on swallow.

In their review of motor control of the diaphragm, Fogarty, Mantila, and Sieck (2018), discuss muscle recruitment of the diaphragm during breathing and other respiratory behaviors. They examined motor unit recruitment across the behaviors of eupnea, response to hypoxia/hypercapnia, deep breath, airway occlusion, and coughing/sneezing. It was concluded that type S (slow, fatigue-resistant) and FR (fast, fatigue-resistant) motor units are recruited for eupnea and hypoxia/hypercapnia (Fogarty, Mantilla, \& Sieck, 2018). Higher force behaviors such as sneezing and coughing required the recruitment of FInt (fast, fatigue-intermediate) and FF (fast, fatigable) type diaphragm motor units (Fogarty, Mantilla, \& Sieck, 2018). A progressive recruitment of the different types of motor units is noted as the force of the behavior increases $(\mathrm{S} \rightarrow \mathrm{FR} \rightarrow \mathrm{FInt} \rightarrow$ FF) (Fogarty, Mantilla, \& Sieck, 2018). The behaviors studied in this review are all recognized as behaviors involving activation of the diaphragm that creates a negative transdiaphragmatic pressure assisting in the execution of the behaviors (Fogarty, Mantilla, \& Sieck, 2018). A goal of this study is to map the diaphragm muscle recruitment that is present during the swallow onto this pre-existing framework.

\section{$\underline{\text { Purpose }}$}

The purpose of this study is to examine the relationship between inspiratory muscle activity of the diaphragm and parasternal during swallow as compared to eupnea (rest breathing), augmented breath (sigh) and cough. 


\section{Hypothesis}

It was hypothesized that there would be no significant difference in amplitude and $\mathrm{RMS}_{75}$ between swallow and eupnea, but cough and augmented breath would be significantly larger. 


\section{CHAPTER 2}

\section{METHODS}

\section{Experiments}

Experiments were performed on five spontaneously breathing adult cats $(3.618 \pm$ $1.3 \mathrm{~kg}$ ). The protocol was approved by the University of Louisville Institutional Animal Care and Use Committees (IACUC). The animals were initially anesthetized with sodium pentobarbital (Lundbeck, Inc., Deerfield, IL) (35 mg/kg) via intravenous administration; supplementary doses were given as needed $(1-3 \mathrm{mg} / \mathrm{kg})$. The right femoral artery and vein were cannulated to monitor blood pressure and administer fluids, respectively, and a tracheostomy was performed. Physiologic levels of end-tidal $\mathrm{CO}_{2}$ (4-4.5\%; Datax Engstrom; Datax Ohmeda, Inc; Madison, WI), body temperature (Homeothermic Blanket Control Unit; Harvard Apparatus; Holliston, MA), and arterial blood gas composition (iSTAT1; Abaxis; Union City, CA) were continually monitored and maintained (Pitts, Rose, Mortensen, Poliacek, Sapienza, Lindsey, Morris, Davenport, \& Bolser, 2013). Electromyograms (EMGs) were recorded using bipolar insulated fine wire electrodes (A-M Systems stainless steel \#791050) according to the technique of Basmajian and Stecko (Basmajian \& Stecko, 1962). Eight muscles were used to evaluate swallow and/or cough function: mylohyoid (MyHy), geniohyoid (GeHy), thyrohyoid (ThHy), thyropharyngeus (ThPh), thyroarytenoid (ThAr), external oblique (EO) parasternal (PS), and costal diaphragm (Dia). Esophageal pressure was measured by placing a balloon catheter connected to a pressure transducer (TA-100; CWE, Inc; 
Ardmore, PA) into the esophagus. Both EMG placement and detection of swallow were conducted as previously described (Pitts, Rose, Mortensen, Poliacek, Sapienza, Lindsey, Morris, Davenport, \& Bolser, 2013; Thexton, Crompton, Owerkowicz, \& German, 2009)

For MyHy and GeHy placement the digastric muscles were blunt dissected away from the surface of the mylohyoid and electrodes were placed in the left mylohyoid. A small horizontal incision was made at the rostral end of the right mylohyoid followed by an incision down the midline for approximately $5 \mathrm{~mm}$ to reveal the geniohyoid muscle. Electrodes were placed $1 \mathrm{~cm}$ from the caudal insertion of the geniohyoid muscle. The thyroarytenoid muscle electrodes were inserted through the cricothyroid window into the anterior portion of the vocal folds, which were visually inspected post-mortem. Minor rotation of the larynx and pharynx counterclockwise revealed the superior laryngeal nerve, which facilitated placement of the thyropharyngeus muscle electrodes. The thyropharyngeus is a fan shaped muscle with the smallest portion attached to the thyroid cartilage; electrodes were placed in the ventral, caudal portion of the muscle overlaying thyroid cartilage within five $\mathrm{mm}$ of the rostral insertion of the muscle. To place electrodes within the cricopharyngeus muscle, the larynx and pharynx were rotated counterclockwise to reveal the posterior aspect of the larynx. The edge of the cricoid cartilage was located by palpation and electrodes were placed in the cricopharyngeus muscle just cranial to the edge of this structure. Thyrohyoid muscle electrodes were inserted approximately five $\mathrm{mm}$ rostral to the attachment to the thyroid cartilage; those for the parasternal muscle were placed in the third intercostal space, just adjacent to the sternum, and the costal diaphragm EMGs were placed through the skin just under the xiphoid process. The positions of all electrodes were confirmed by visual inspection 
(following electrode placement and post-mortem) and by EMG activity patterns during breathing and swallow.

\section{$\underline{\text { Stimuli }}$}

Swallow was induced by introducing three ccs of water into the pharynx via a one-inch long, thin polyethylene catheter (outer diameter 0.5-1.0 $\mathrm{mm}$ ) attached to a syringe. Cough was induced by mechanical stimulation of the extra and intra-thoracic trachea using a thin polyethylene catheter (diameter $1.27 \mathrm{~mm}$ ). The catheter was manually rotated along the length of the intrathoracic trachea. Augmented breaths (sighs) occur frequently during the experimental preparation and animals were freely breathing to analyze during baseline eupneic conditions.

\section{$\underline{\text { Motor patterns }}$}

Swallowing was defined as an overlapping mylohyoid, thyropharyngeus, thyroarytenoid, inspiratory muscle activity (parasternal/diaphragm) combined with a drop in esophageal pressure (Figure 1). Swallow can be clearly differentiated from other behaviors (augmented breath, laryngeal elevation, cough, expiration reflex, and aspiration reflex) by this activity pattern (German, Crompton, \& Thexton, 2009; Miller \& Sherrington, 1915; Pitts, Rose, Mortensen, Poliacek, Sapienza, Lindsey, Morris, Davenport, \& Bolser, 2013; Thexton, Crompton, \& German, 2007; Thexton, Crompton, Owerkowicz, \& German, 2009). Cough was defined as a burst of activity in the parasternal EMG, followed by (and partially overlapping) a burst in the thyroarytenoid and external oblique, along with a negative to positive change in esophageal pressure (Figure 2). Augmented breaths were defined similarly to eupnea but with increased amplitude of muscle activations relative to the surrounding eupnea (Figure 3). Eupnea 
was defined as periodic activation of diaphragm and parasternal accompanied by a drop in esophageal pressure.

\section{Data processing and statistical analysis}

EMGs were recorded and analyzed using "Spike 2" Version 7 (Cambridge Electronic Design, United Kingdom). EMGs were rectified and maximum amplitude of muscle activation was calculated. Muscle recruitment of the diaphragm and parasternal muscles was analyzed by calculating the root mean square during the first $75 \mathrm{~ms}$ of the behavior $\left(\mathrm{RMS}_{75}\right)$ via the technique of Sieck (Seven, Mantilla, \& Sieck, 2014). EMG amplitude measures were normalized to the largest breath and are presented as \% of maximum during eupnea.

A mean \pm standard deviation (SD) was calculated for each animal, and then averaged for each condition across animals. For statistical analysis a Student's paired t-test was performed and a difference was considered significant if the $p$-value was less than 0.05. Additionally, Pearson Product-Moment Correlation Coefficient $(r)$ was computed to assess relationships between esophageal pressure change and inspiratory muscle activity ( $\mathrm{RMS}_{75}$ and maximum amplitude for Dia and PS). Values between .50 and .70 were considered moderate, $.70-.90$ considered high. 


\section{CHAPTER 3}

\section{RESULTS}

\section{$\underline{\text { Inspiratory muscle activation across behaviors }}$}

Table 1 reports the change in diaphragm and parasternal activation in all behaviors as compared to swallow. Means from all five animals are reported. A significant difference $(p<0.05)$ in maximum muscle activation of the Ps was found in the behaviors of eupnea, augmented breath, and cough. Maximum amplitude of the Dia was found to be significantly different for the behaviors of augmented breath and cough. Muscle recruitment $\left(\mathrm{RMS}_{75}\right)$ of Ps was shown to be significantly different from swallow for the behavior of eupnea. Figures 4 and 5 represent maximum amplitude of the diaphragm and parasternal muscles during the different behaviors respectively.

\section{Correlation between diaphragm and parasternal activation}

Pearson Product-Moment Correlations were calculated to evaluate the relationship between muscle activity of the parasternal and diaphragm muscles across all behaviors. For maximum amplitude of muscle activation (\% of eupnea), parasternal and diaphragm were moderately correlated $(r=0.58)$. For $\mathrm{RMS}_{75}$, the two muscles were moderately correlated with a correlation coefficient of $r=0.68$.

\section{Correlation between esophageal pressure and muscle activation}

Table 2 shows all Pearson Product-Moment Correlations for EMG amplitude data compared to esophageal pressure change for each behavior. This analysis resulted in two moderate negative correlations and one high negative correlation: esophageal pressure 
and maximum amplitude of diaphragm activation during swallow $(r=-0.67)$; esophageal pressure and maximum amplitude of diaphragm activation during augmented breath $(r=-$ .62); and esophageal pressure and maximum amplitude of parasternal muscle during $\operatorname{cough}(r=-.70)$.

\section{Table 1}

Muscle activation across behaviors compared to swallow

\begin{tabular}{|c|c|c|c|c|c|c|c|c|c|c|c|}
\hline & \multicolumn{3}{|c|}{ Swallow } & \multicolumn{3}{|c|}{ Eupnea } & \multirow[b]{2}{*}{$p$-value } & \multicolumn{2}{|l|}{$\begin{array}{l}\text { Augmented } \\
\text { Breath }\end{array}$} & \multicolumn{2}{|l|}{ Cough } \\
\hline & Mean & \pm & SD & Mean & \pm & SD & & Mean \pm SD & $p$-value & Mean \pm SD & $p$-value \\
\hline \multicolumn{12}{|c|}{ Root Mean Square (RMS75) } \\
\hline Parasternal & 208 & \pm & 114 & 76 & \pm & 14 & 0.04 & $100 \pm 41$ & 0.05 & $159 \pm 66$ & 0.41 \\
\hline Diaphragm & 117 & \pm & 51 & 72 & \pm & 16 & 0.16 & $94 \pm 37$ & 0.49 & $141 \pm 69$ & 0.49 \\
\hline \multicolumn{12}{|c|}{ Amplitude (\% max of eupnea) } \\
\hline Parasternal & 180 & \pm & 64 & 75 & \pm & 12 & 0.02 & $366 \pm 98$ & 0.005 & $276 \pm 85$ & 0.02 \\
\hline Diaphragm & 122 & \pm & 61 & 79 & \pm & 13 & 0.27 & $229 \pm 70$ & $<0.001$ & $399 \pm 231$ & 0.04 \\
\hline
\end{tabular}

Significant if $p<0.05$

\section{Table 2}

Correlation of esophageal pressure to muscle activation

\begin{tabular}{lcccc}
\hline Behavior & $\begin{array}{c}\text { RMS } \\
\text { Diaphragm }\end{array}$ & $\begin{array}{c}\text { RMS } \\
\text { Parasternal }\end{array}$ & $\begin{array}{c}\text { Diaphragm Max } \\
\text { Amplitude }\end{array}$ & $\begin{array}{c}\text { Parasternal Max } \\
\text { Amplitude }\end{array}$ \\
\hline $\begin{array}{l}\text { Eupnea } \\
\text { Augmented }\end{array}$ & 0.10 & 0.12 & -0.50 & -0.35 \\
Breath & 0.36 & 0.22 & $\mathbf{- 0 . 6 2}$ & -0.27 \\
Swallow & -0.39 & -0.19 & $\mathbf{- 0 . 6 7}$ & -0.28 \\
Cough & 0.38 & -0.22 & -0.46 & $\mathbf{- 0 . 7 0 *}$ \\
\hline
\end{tabular}

Bold for moderate $r$-value

Bold $+*$ for high $r$-value 


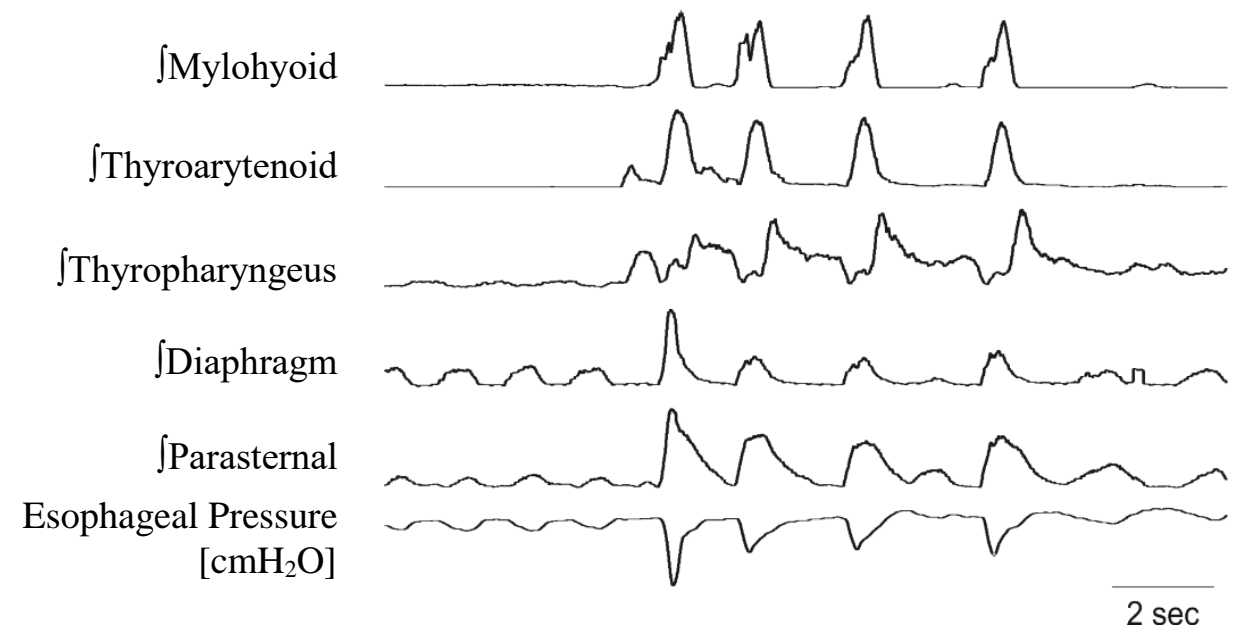

Figure 1. Motor patterns utilized to identify swallow.

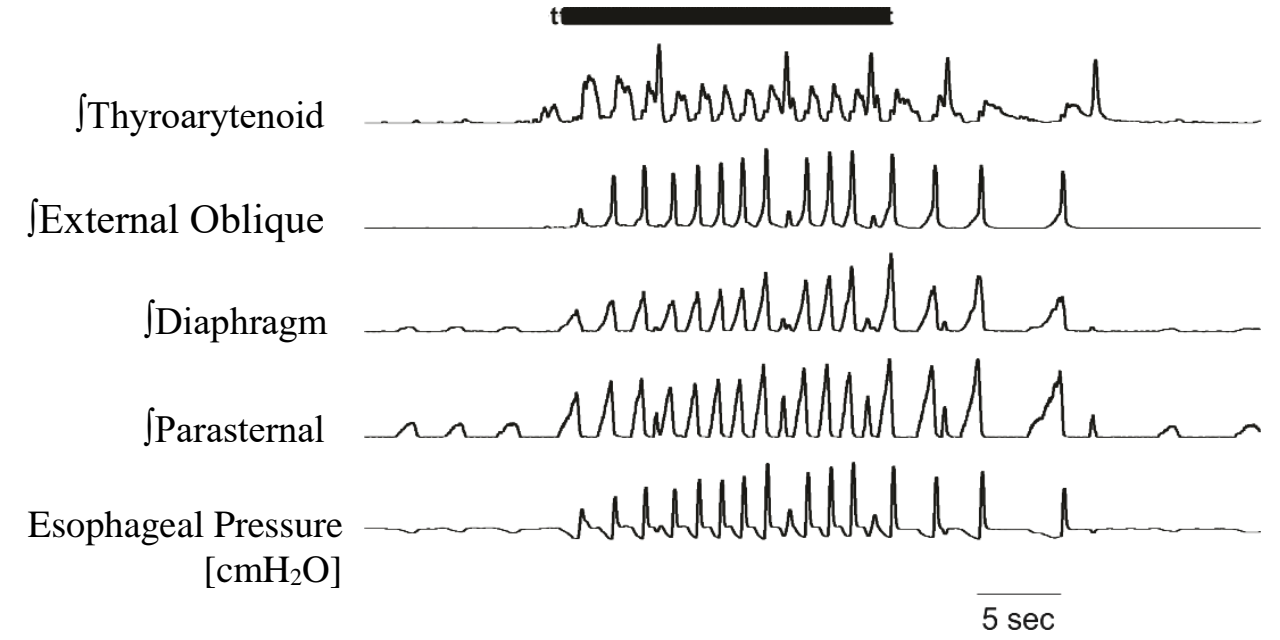

Figure 2. Motor patterns utilized to identify cough. 


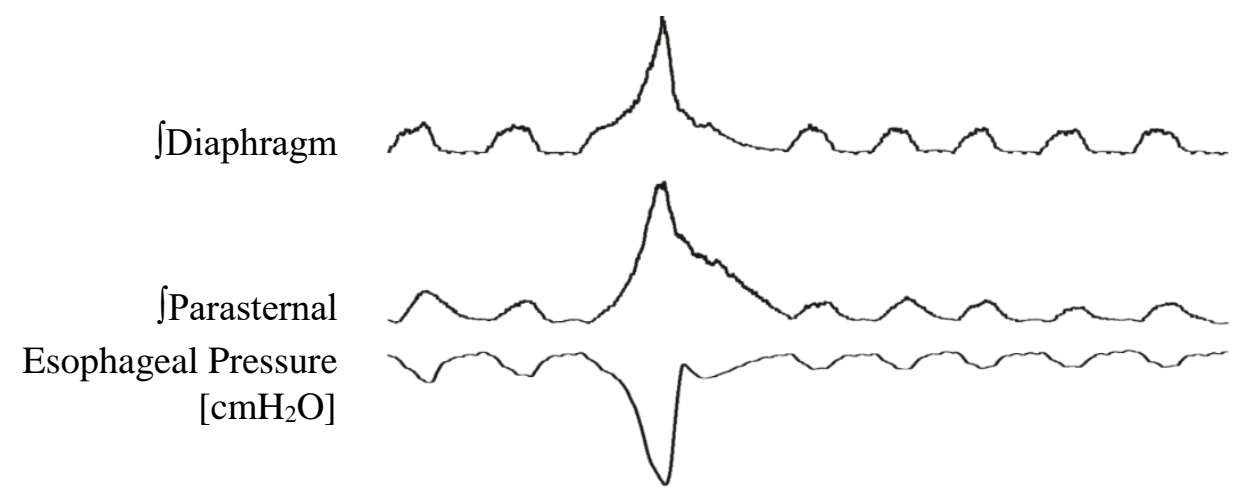

Figure 3. Motor patterns utilized to identify augmented breath (sigh).

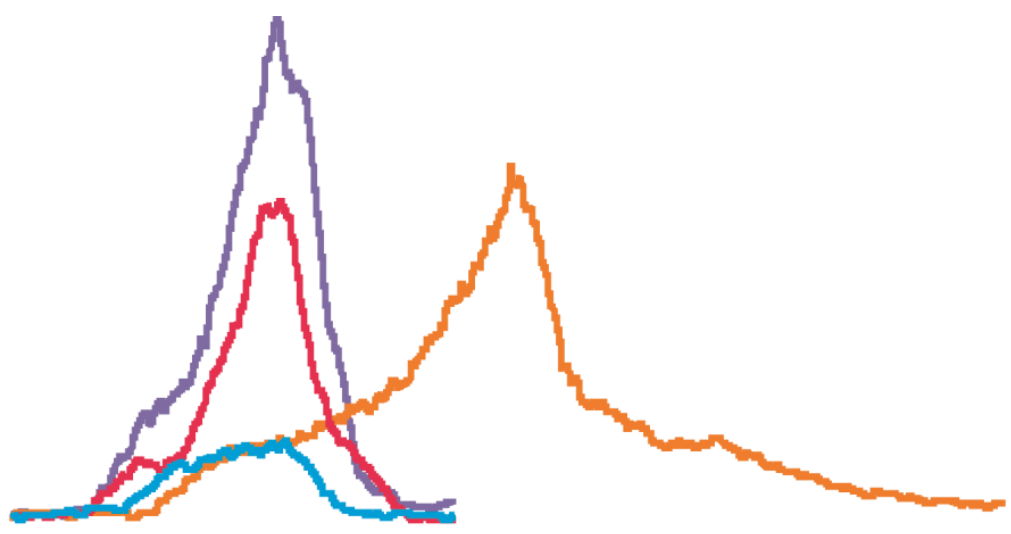

4 sec

Figure 4. Overlapping maximum amplitudes of the diaphragm during different behaviors: eupnea (blue), sigh (orange), swallow (red), and cough (purple). 


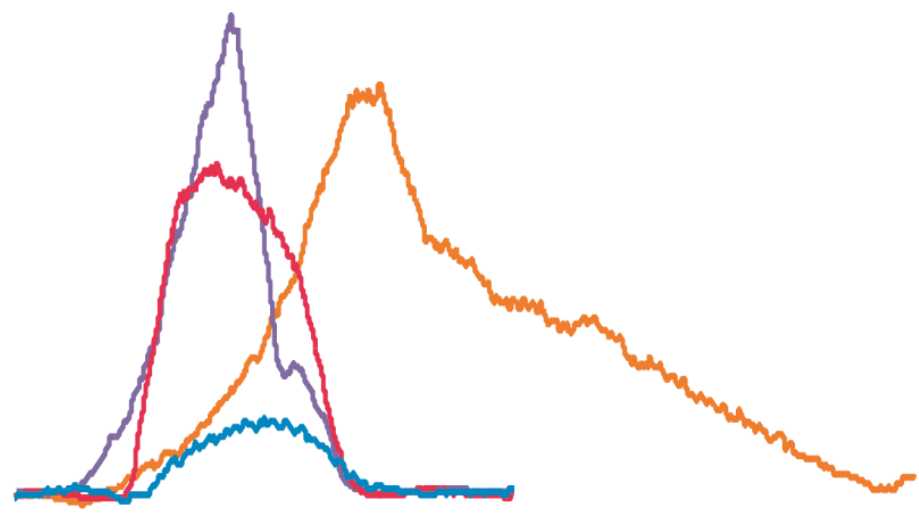

$4 \mathrm{sec}$

Figure 5. Overlapping maximum amplitudes of the parasternal during different behaviors: eupnea (blue), sigh (orange), swallow (red), and cough (purple). 


\section{CHAPTER 4}

\section{DISCUSSION}

This is the first study to examine maximum amplitude of muscle activation and muscle recruitment $\left(\mathrm{RMS}_{75}\right)$ for comparison across the behaviors of swallow, cough, eupnea, and augmented breath. Our results demonstrate that swallow is comparable to eupnea for $\mathrm{RMS}_{75}$ and maximum amplitude of diaphragm. However, the swallow behavior results in a significantly larger $\mathrm{RMS}_{75}$ and maximum amplitude of diaphragm activation of the parasternal muscle. The behaviors of cough and augmented breath result in larger amplitude of muscle activation for both the parasternal and diaphragm muscles, compared to swallow. Our results also demonstrate a moderate negative correlation between inspiratory musculature and esophageal pressure during swallow, indicating that the activity of the inspiratory muscle contributes to the negative deflection of the esophagus that occurs during swallow. These results add additional evidence of the importance of inspiratory muscle activity during swallow.

\section{$\underline{\text { Swallow motor pattern }}$}

This project is a continueation of a series of studies to further elucidate the control of swallow, and more specifically the role of inspiratory muscle activity during swallow. A previous study investigating the coordination of cough and swallow found presence of diaphragm and parasternal activity during swallow (Pitts, Rose, Mortensen, Poliaček, Sapienza, Lindsey, Morris, Davenport, \& Bolser, 2013). Furthermore, an investigation of 
the role of the cerebellum during swallow, the parasternal and diaphragm muscles were to found to have decreased activation post-cerebellectomy, but the activation of these inspiratory muscles was not affected during respiration (Reed, English, English, Huff, Poliacek, Musselwhite, Howland, Bolser, \& Pitts, 2019). Another study found that an upper abdominal laparotomy in cats lead to the majority of swallows taking place during the inspiratory phase or in a transitional phase between inspiration and expiration (Pitts, Rose, Poliacek, Condrey, Davenport, \& Bolser, 2015). This is a significant change as swallows typically take place during the expiratory phase of breathing. The results of this study indicate the importance of a peripheral feedback mechanism for swallow/breathing coordination (Pitts, Rose, Poliacek, Condrey, Davenport, \& Bolser, 2015). All of these studies work to investigate the control of swallow. This study continues this investigation by examining the muscle activation and recruitment of inspiratory muscles during swallow compared to other behaviors.

\section{$\underline{\text { Recruitment of inspiratory muscles across airway behaviors }}$}

Recruitment of diaphragm muscle motor unit types is extensively outlined by Fogarty, Mantilla, and Seick (2018) in their review of motor control of the diaphragm. As mentioned previously, the four motor unit types are S, FR, FInt, and FF, recruited in that order (Fogarty, Mantilla, \& Sieck, 2018). For rhythmic breathing, type S motor units are sufficient (Fogarty, Mantilla, \& Sieck, 2018). An augmented breath will require the recruitment of type FR motor units while type FInt and FF are necessary for behaviors such as cough that require increased force (Fogarty, Mantilla, \& Sieck, 2018). While our results did not demonstrate a significant change in muscle recruitment of diaphragm across behaviors via $\mathrm{RMS}_{75}$, the recruitment of the parasternal was significantly larger for 
swallow as compared to eupnea. There was also a significant difference for maximum amplitude of muscle activation for the parasternal and diaphragm for swallow compared to augmented breath and cough.

The diaphragm muscle is innervated by motor neurons of the phrenic nerve, which is comprised of spinal nerves cervical roots three to five in the human and phrenic premotor neurons located in the medulla (Mantilla \& Sieck, 2008; Muller Botha, 1957). The parasternal muscle is innervated by thoracic spinal nerves (Andersen \& Sears, 1964). In addition to the motor and premotor neurons involved in activation of these muscles, there are also different central pattern generators (CPG) that are believed to coordinate the actions of all muscles involved in different airway behaviors such as respiration, coughing, sneezing, and swallow (Fogarty, Mantilla, \& Sieck, 2018). The location of these CPG's is thought to be the brain stem (Fogarty, Mantilla, \& Sieck, 2018). The results of our study leads to the conclusion that both the parasternal and diaphragm muscles are important for swallow. The nerve supply of these muscles originates from different regions of the spinal cord (Andersen \& Sears, 1964; Muller Botha, 1957). It can therefore be concluded that both the cervical and thoracic spinal cord is necessary for appropriate behavior execution of swallow.

\section{Clinical relevance}

Due to the role of inspiratory musculature on swallow not yet fully being defined, the function of these muscles is not included in screening or treatment protocols for dysphagia. However, the results of this study and others like it continue to indicate their importance. First and foremost, this information should lead to heightened focus for dysphagia screening in populations in which it is known that inspiratory muscle function 
may be compromised. The cSCI population is of particular interest due to inspiratory muscle involvement (Muller Botha, 1957). In this population, presence of dysphagia acutely post-injury is recognized however there is a misconception of its resolution with time alone (Savic, DeVivo, Frankel, Jamous, Soni, \& Charlifue, 2017). Increased focus on the long-term monitoring and treatment of dysphagia in this group could lead to decreased risk for pulmonary complications and morbidity associated with their injuries (Frankel, Coll, Charlifue, Whiteneck, Gardner, Jamous, Krishnan, Nuseibeh, Savic, \& Sett, 1998).

In terms of continued research focus, inspiratory musculature involvement during swallow should be investigated in other populations with known respiratory complications. The risk for dysphagia is well recognized in the chronic obstructive pulmonary disorder (COPD) population, attributed to affected individuals swallowing during the inspiratory phase rather than the expiratory phase of breathing as is typical in the normal swallow (Shaker, Li, Ren, Townsend, Dodds, Martin, Kern, \& Rynders, 1992). Research on the role of inspiratory muscle recruitment during swallow in COPD patients could help to further elucidate this disordered swallow. Conversely, individuals with obesity are a population with recognized respiratory difficulties (Zammit, Liddicoat, Moonsie, \& Makker, 2010) but not recognized swallowing issues. Research in the swallow behaviors of obese individuals would be beneficial to the understanding of the role inspiratory musculature plays on swallow.

The conclusion that inspiratory muscle activation contributes to swallow should lead to the development of treatment strategies for dysphagia that target these muscles. An example of a strategy that could address such muscles is inspiratory muscle strength 
training (IMST) (Dall'Ago, Chiappa, Guths, Stein, \& Ribeiro, 2006). There has been previous research focus on the role of expiratory muscle strength training (EMST) in dysphagia treatment, specifically within neurodegenerative disease populations such as Parkinson's and Huntington's disease (Pitts, Bolser, Rosenbek, Troche, Okun, \& Sapienza, 2009; Reyes, Cruickshank, Thompson, Ziman, \& Nosaka, 2014; Troche, Okun, Rosenbek, Musson, Fernandez, Rodriguez, Romrell, Pitts, Wheeler-Hegland, \& Sapienza, 2010). While this research has demonstrated the effectiveness of EMST in improving swallow in these populations, there has been little to no research in the effectiveness of IMST in treating swallow. The focus of previous IMST research has been the impact on ventilatory capacity and endurance (Leith \& Bradley, 1976; Martin, Smith, Davenport, Harman, Gonzalez-Rothi, Baz, Layon, Banner, Caruso, Deoghare, Huang, \& Gabrielli, 2011). The effects of IMST on swallow should be investigated. The consistent results of our research indicate the importance of inspiratory muscles for swallow and these muscles should, therefore, be the subject of treatment protocol research.

\section{$\underline{\text { Limitations }}$}

A potential limitation of this study is the experiment utilizing anesthetized cats. The use of the anesthetic sodium pentobarbital has been seen to cause decreased respiratory drive as previously discussed by Pitts and colleagues (2013). However, it is believed that the behaviors of interest (swallow, cough, eupnea, and sigh) observed in these experiments were not diminished by the use of this anesthetic.

\section{$\underline{\text { Conclusions }}$}

The results of our study demonstrate that there is significant difference in inspiratory muscle activation across the behaviors of swallow, cough, sigh, and eupnea. 
There is also a correlation between inspiratory muscle activation and change in esophageal pressure. These results indicate the importance of inspiratory musculature to the behavior of swallow. Our study adds to the existing research investigating the control of swallow. The results of our study and others like it should lead to increased attention and awareness for the potential of swallowing difficulties in populations with impaired inspiratory muscle function (cSCI, COPD, obesity), as well as continued investigation in the efficacy of IMST on dysphagia rehabilitation. 


\section{REFERENCES}

Andersen, P., \& Sears, T. A. (1964). The Mechanical Properties and Innervation of Fast and Slow Motor Units in the Intercostal Muscles of the Cat. J Physiol, 173, 114129.

Basmajian, J., \& Stecko, G. (1962). A new bipolar electrode for electromyography. Journal of Applied Physiology, 17(5), 849-849.

Chaw, E. S., K., Castillo, K., Wong, S.L., \& Chang, J. (2012). Dysphagia and Associated Respiratory Considerations in Cervical Spinal Cord Inury. Topics in Spinal Cord Injury Rehabilitation, 18(4), 291-299.

Dall'Ago, P., Chiappa, G. R., Guths, H., Stein, R., \& Ribeiro, J. P. (2006). Inspiratory muscle training in patients with heart failure and inspiratory muscle weakness: a randomized trial. J Am Coll Cardiol, 47(4), 757-763.

Dray, T. G., Hillel, A. D., \& Miller, R. M. (1998). Dysphagia caused by neurologic deficits. Otolaryngol Clin North Am, 31(3), 507-524.

Ertekin, C. (2014). Electrophysiological evaluation of oropharyngeal Dysphagia in Parkinson's disease. J Mov Disord, 7(2), 31-56.

Eslick, G. D., \& Talley, N. J. (2008). Dysphagia: epidemiology, risk factors and impact on quality of life--a population-based study. Aliment Pharmacol Ther, 27(10), 971-979.

Fogarty, M. J., Mantilla, C. B., \& Sieck, G. C. (2018). Breathing: Motor Control of Diaphragm Muscle. Physiology (Bethesda), 33(2), 113-126.

Frankel, H. L., Coll, J. R., Charlifue, S. W., Whiteneck, G. G., Gardner, B. P., Jamous, M. A., . . . Sett, P. (1998). Long-term survival in spinal cord injury: a fifty year investigation. Spinal Cord, 36(4), 266-274.

Garon, B. R., Sierzant, T., \& Ormiston, C. (2009). Silent aspiration: results of 2,000 video fluoroscopic evaluations. Journal of Neuroscience Nursing, 41(4), 178-185.

German, R. Z., Crompton, A. W., \& Thexton, A. J. (2009). Integration of the reflex pharyngeal swallow into rhythmic oral activity in a neurologically intact pig model. J Neurophysiol, 102(2), 1017-1025. 
Hardemark Cedborg, A. I., Sundman, E., Boden, K., Hedstrom, H. W., Kuylenstierna, R., Ekberg, O., \& Eriksson, L. I. (2009). Co-ordination of spontaneous swallowing with respiratory airflow and diaphragmatic and abdominal muscle activity in healthy adult humans. Exp Physiol, 94(4), 459-468.

Jackson, A. B., \& Groomes, T. E. (1994). Incidence of respiratory complications following spinal cord injury. Arch Phys Med Rehabil, 75(3), 270-275.

Kirshblum, S. C., Burns, S. P., Biering-Sorensen, F., Donovan, W., Graves, D. E., Jha, A., ... Waring, W. . (2011). Internation standards for neurological classification of spinal cord injury. The Journal of Spinal Cord Medicine, 34(6), 535-546.

Lang, I. M. (2009). Brain stem control of the phases of swallowing. Dysphagia, 24, 333348.

Leith, D. E., \& Bradley, M. (1976). Ventilatory muscle strength and endurance training. J Appl Physiol, 41(4), 508-516.

Mandaville, A., Ray, A., Robertson, H., Foster, C., \& Jesser, C. (2014). A retrospective review of swallow dysfunction in patients with severe traumatic brain injury. Dysphagia, 29(3), 310-318.

Mantilla, C. B., \& Sieck, G. C. (2008). Key aspects of phrenic motoneuron and diaphragm muscle development during the perinatal period. J Appl Physiol (1985), 104(6), 1818-1827.

Marckwald, M. (1888). The movements of respiration and their innervation of the rabbit.

Martin, A. D., Smith, B. K., Davenport, P. D., Harman, E., Gonzalez-Rothi, R. J., Baz, M., . . Gabrielli, A. (2011). Inspiratory muscle strength training improves weaning outcome in failure to wean patients: a randomized trial. Crit Care, 15(2), R84.

Martino, R., Foley, N., Bhogal, S., Diamant, N., Speechley, M., \& Teasell, R. (2005). Dysphagia after stroke: incidence, diagnosis, and pulmonary complications. Stroke, 36(12), 2756-2763.

Matsuo, K. P., J. B. (2008). Anatomy and physiology of feeding and swallowing - normal and abnormal. Physical Medicine and Rehabilitation Clinics, 19(4), 691-707.

Miller, F., \& Sherrington, C. (1915). Some observations on the bucco-pharyngeal stage of reflex deglutition in the cat. Experimental Physiology, 9(2), 147-186.

Muller Botha, G. S. (1957). The anatomy of phrenic nerve termination and the motor innervation of the diaphragm. Thorax, 12(1), 50-56. 
National Spinal Cord Injury Statistical Center (2019). Facts and figures at a glance. In. Birmingham, AL: University of Alabama at Birmingham.

Pitts, T., Bolser, D., Rosenbek, J., Troche, M., Okun, M. S., \& Sapienza, C. (2009). Impact of expiratory muscle strength training on voluntary cough and swallow function in Parkinson disease. Chest, 135(5), 1301-1308.

Pitts, T., Poliacek, I., Rose, M. J., Reed, M. D., Condrey, J. A., Tsai, H. W., . . Bolser, D. C. (2018). Neurons in the dorsomedial medulla contribute to swallow pattern generation: Evidence of inspiratory activity during swallow. PLoS One, 13(7), e0199903.

Pitts, T., Rose, M. J., Mortensen, A. N., Poliaček, I., Sapienza, C. M., Lindsey, B. G., . . . Bolser, D. C. (2013). Coordination of cough and swallow: a meta-behavioral response to aspiration. Respiratory Physiology \& Neurobiology, 189(3), 543-551.

Pitts, T., Rose, M. J., Poliacek, I., Condrey, J., Davenport, P. W., \& Bolser, D. C. (2015). Effect of laparotomy on the swallow-breathing relationship in the cat. Lung, 193(1), 129-133.

Ramsey, D., Smithard, D., \& Kalra, L. (2005). Silent aspiration: what do we know? Dysphagia, 20(3), 218-225.

Reed, M. D., English, M., English, C., Huff, A., Poliacek, I., Musselwhite, M. N., . . Pitts, T. (2019). The role of the cerebellum in control of swallow: evidence of inspiratory activity during swallow. Lung.

Reyes, A., Cruickshank, T., Thompson, J., Ziman, M., \& Nosaka, K. (2014). Surface electromyograph activity of submental muscles during swallowing and expiratory muscle training tasks in Huntington's disease patients. J Electromyogr Kinesiol, 24(1), 153-158.

Robbins, J., Coyle, J., Rosenbek, J., Roecker, E., \& Wood, J. (1999). Differentiation of normal and abnormal airway protection during swallowing using the penetrationaspiration scale. Dysphagia, 14(4), 228-232.

Savic, G., DeVivo, M. J., Frankel, H. L., Jamous, M. A., Soni, B. M., \& Charlifue, S. (2017). Long-term survival after traumatic spinal cord injury: a 70-year British study. Spinal Cord, 55(7), 651-658.

Seven, Y.B., Mantilla, C. B., \& Sieck, G. C. (2014). Recruitment of rat diaphragm motor units across motor behaviors with different levels of diaphragm activation. Journal of Applied Physiolog, 117(11), 1308-1316. 
Shaker, R., Li, Q., Ren, J., Townsend, W. F., Dodds, W. J., Martin, B. J., . . Rynders, A. (1992). Coordination of deglutition and phases of respiration: effect of aging, tachypnea, bolus volume, and chronic obstructive pulmonary disease. Am J Physiol, 263(5 Pt 1), G750-755.

Shem, K., Castillo, K., Wong, S., \& Chang, J. (2011). Dysphagia in individuals with tetrapliegia: incidence and risk factors. The Journal of Spinal Cord Medicine, 34(1), 85-92.

Smithard, D. G. (2015). Dysphagia: prevalence, management and the community nurse. Community Pract, 88(10), 32-35.

Thexton, A. J., Crompton, A. W., \& German, R. Z. (2007). Electromyographic activity during the reflex pharyngeal swallow in the pig: Doty and Bosma (1956) revisited. J Appl Physiol, 102(2), 587-600.

Thexton, A. J., Crompton, A. W., Owerkowicz, T., \& German, R. Z. (2009). Impact of rhythmic oral activity on the timing of muscle activation in the swallow of the decerebrate pig. J Neurophysiol, 101(3), 1386-1393.

Troche, M. S., Okun, M. S., Rosenbek, J. C., Musson, N., Fernandez, H. H., Rodriguez, R., ... Sapienza, C. M. (2010). Aspiration and swallowing in Parkinson disease and rehabilitation with EMST: a randomized trial. Neurology, 75(21), 1912-1919.

Wolf, C. \& Meiners, T. H. (2003). Dysphagia in patients with acute cervical spinal cord injury. Spinal Cord, 41, 347-353.

Zammit, C., Liddicoat, H., Moonsie, I., \& Makker, H. (2010). Obesity and respiratory diseases. Int J Gen Med, 3, 335-343. 


\section{APPENDIX: ABBREVIATIONS}

COPD

CPG

cSCI

EMG

EMST

EO

$\mathrm{FF}$

FInt

FR

GeHy

IACUC

IMST

MyHy

PS

RMS

$\mathrm{S}$

SD

ThAr

ThHy

$\mathrm{ThPh}$
Chronic Obstructive Pulmonary Disorder

Central Pattern Generator

cervical spinal cord injury

electromyogram

Expiratory Muscle Strength Training

external oblique

fast, fatigable

fast, fatigue-intermittent

fast, fatigue resistant

geniohyoid

Institutional Animal Care and Use Committee

Inspiratory Muscle Strength Training

mylohyoid

parasternal

root mean square

slow, fatigue resistant

standard deviation

thyroarytenoid

thyrohyoid

thyropharyngeus 


\section{CURRICULUM VITAE}

NAME:

ADDRESS:

DOB:

EDUCATION \& TRAINING:

PROFESSIONAL SOCIETIES:

PRESENTATIONS: $\quad$ English, A., Reed, M., Huff, A., Pitts, T. Relationship between esophageal pressure and inspiratory muscle activity. Kentucky Speech and Hearing Association Conference, Lexington, KY: February 2019.

English, A. Transdiaphragmatic pressure. University of Louisville Communicative Disorders Research in Progress, Louisville, KY: November 2017. 